\title{
Chapter 3 \\ The Features of Natural and Artificial \\ Recovery in Quarries of the Forest-Tundra Zone of Western Siberia
}

\author{
Elena Koptseva and Alexander Egorov
}

\begin{abstract}
The features of natural recovery and artificial restoration of quarries in northern regions of Western Siberia is analysed in this article. The effectiveness of restoration is compared with natural revegetation results. It is shown that the development of restoration projects requires a comprehensive consideration of environmental conditions. General recommendations for restoration of quarry areas are formulated.
\end{abstract}

\subsection{Introduction}

Quarry is a common type of land-use in northern regions of Russia. A quarry is an open-cut excavation that reaches over a considerable transversal size. It is used for extraction of sand, loam, stone and others. Post-operative quarry area remains without vegetation and fertile soil cover for a long time. Environmental conditions in quarries are very specific for plants, because soil is nutrient poor and erosion processes are very active (Abakumov et al. 2011). Usually, quarry area has a complex internal anthropogenic relief in the form of high peaks, pits and furrows.

Publication activity on the issue of disturbed lands restoration shows the absence of consensus. What is more effective: natural or artificial recovery? Previous publications indicate that the process of natural revegetation may take many years and depend on many environmental factors (Borgergard 1990; Sumina 1998).

\footnotetext{
E. Koptseva $(\bowtie)$

Saint-Petersburg State University, Saint-Petersburg, Russia e-mail: ekoptseva@hotmail.com
}

\author{
A. Egorov \\ Saint-Petersburg State University, Saint-Petersburg, Russia \\ Saint-Petersburg State Forest Technical University, Saint-Petersburg, Russia \\ (C) The Author(s) 2017 \\ K. Latola, H. Savela (eds.), The Interconnected Arctic - UArctic Congress 2016, \\ Springer Polar Sciences, DOI 10.1007/978-3-319-57532-2_3
}


Information about efficiency of artificial land restoration is contradictory and practical approaches used for the restoration are not summarized. In some regions of Russia, for example in the Yamal-Nenets Autonomous District, the regional standards for restoration of disturbed lands are still absent. The nationwide standards have to use but they do not fully take into account peculiarities of northern ecosystems.

Gained actual experience in land restoration, as well the capacity of northern ecosystems to natural recovery should be considered in the development of regional standards. In this context, a comparison of natural recovery effectiveness with artificial restoration of disturbed lands, as well as generalization of accumulated practical experience on restoration, is particularly relevant for the Far North of Russia.

\subsection{Materials and Methods}

Natural and artificial vegetation recovery on quarries was studied in several geographical locations in the Yamal-Nenets Autonomous District of Northwest Siberia (Fig. 3.1).

The study area is covered by forest-tundra plant communities. Larch, larchspruce and larch-pine sparse forest and palsa mires are predominated in the region (Fig. 3.2 a, b). Species of shrubs (as Betula nana), dwarf shrubs (as Ledum palustre, Vaccinium myrtillus, V. uliginosum, V. vitis-idaea, Empetrum hermaphroditum), mosses (as Pleurozium schreberi, Hylocomium splendens) and fruticose lichens (as Cladonia and Cetraria species) have the highest frequency and are much more abundant in undisturbed zonal vegetation.

Natural vegetation recovery as well as artificial processes was investigated from 2013 to 2016 on sandy or sandy loam quarries. Sometimes the substrate contained a small admixture of gravel and pebble. Development of quarries was finished at different times (from a few to 40 and more years ago). The basic method of study was the inventory of vegetation in ten quarries by sample plots from 25 to 400 sq.m. The total number of plots was more than 40. In each sample plot we collected common data on:

- total list of vascular and non-vascular species;

- total vegetation cover (\%), projective cover for each of vascular and non-vascular species (\%), projective cover (\%) for each of the main plant types (woody plants, herbs, forbs, graminoids, shurbs, mosses and lichens);

- the number and the height of layers of vegetation.

Community types were distinguished according to Cajander's theory of forest types by taking into account the combination of dominant species (Barrington 1927).

Granulometric analysis of soil substrates was performed according to the method of sifting cylinder (Soil Sampling and Methods of Analysis 2008). 


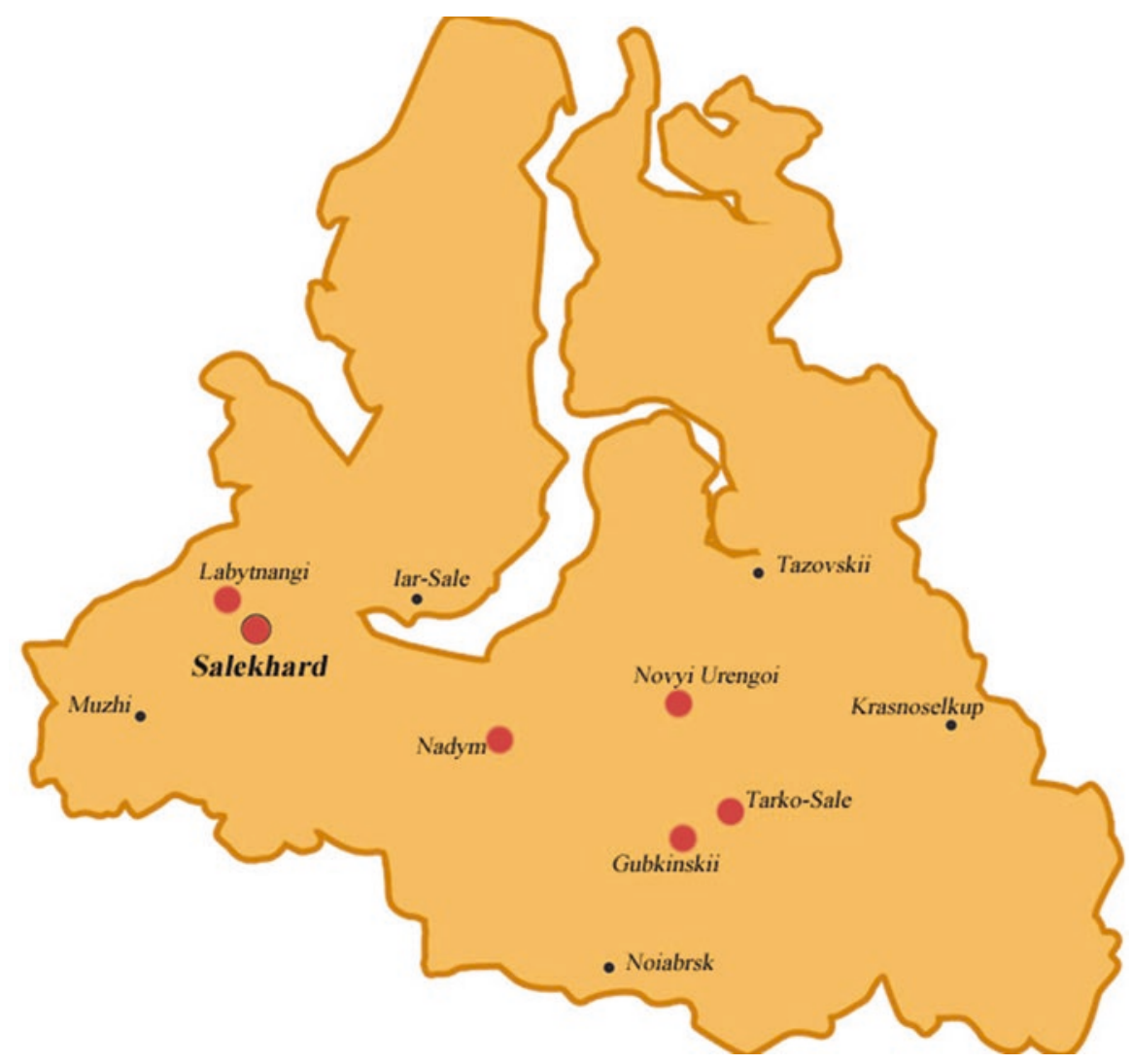

Fig. 3.1 The map of the Yamal-Nenets Autonomous District. Locations of field data collection sites are indicated by red marks

\subsubsection{Natural Recovery of Vegetation}

In quarries, natural recovery takes place in several stages. In this study, four successional stages were distinguished. Sparse vegetation varying in the species composition of plants is formed in the quarry during the first few years (Fig. 3.3a). This stage of the recovery can be described as an ecological chaos because ecologically different species coexist in such habitats. As the result, the maximum of plant species diversity is present in this stage. Interactions between plants are extremely weak and instable. Usually such plant communities are named as pioneers (Walker and del Moral 2008). A small proportion of native species (not more than 15\%) from undisturbed surrounding plant communities comes to the quarry during first years of the recovery. This is because most of the native plants have competitive or stress tolerant ecological strategies whereas the environmental conditions in quarries are favorable for ruderal species (Forbes et al. 2001). Species such as willow herb, chamomile, 


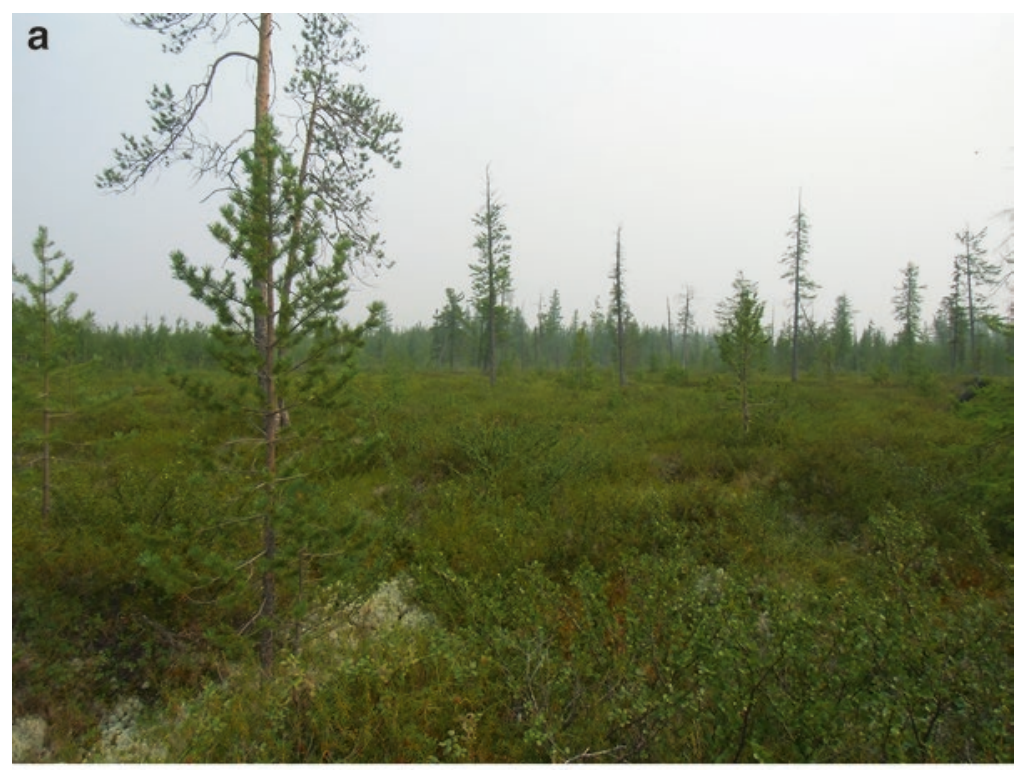

b

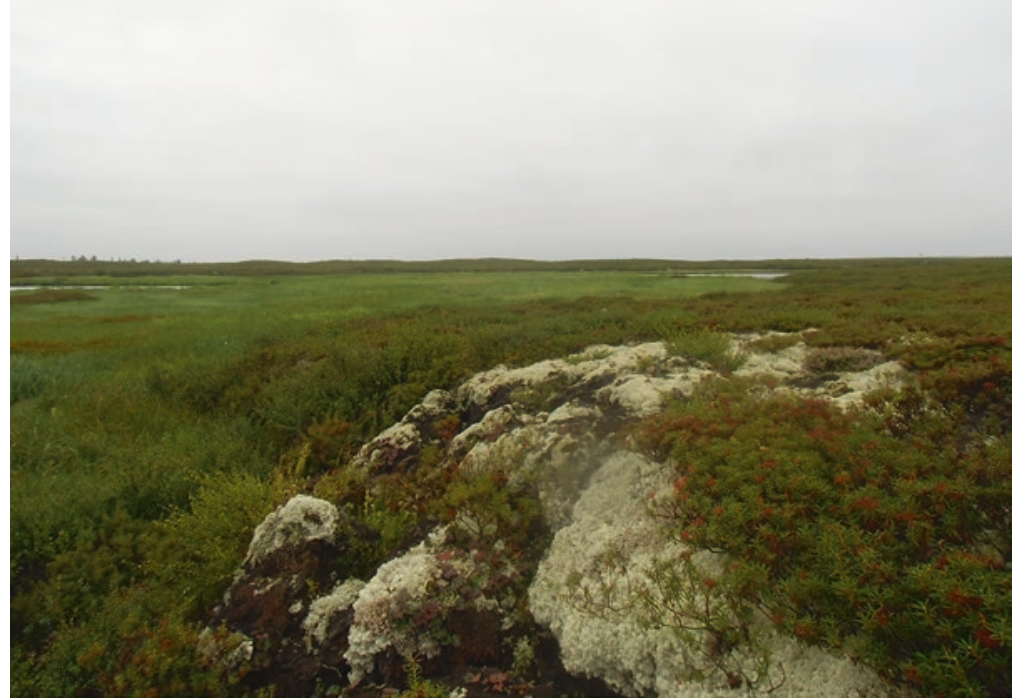

Fig. 3.2 Natural undisturbed sparse forest (a) and palsa (b) in the region (Photographs by: E. Koptseva)

coltsfoot, knotgrass, horsetail, fescue grass, snow grass are the most typical for this stage on the study areas.

Horizontal and vertical structure of vegetation also has not yet formed at this initial stage (Walker and del Moral 2008). As a general rule, plants varied in height 
are present in pioneer communities. Horizontally, vegetation begins to form from separate patches as shown in Fig. 3.3a. Patchy vegetation structure is probably due to clonal growth of some plants for example like willow herb or coltsfoot. So, more than $50 \%$ of common species in quarries prefer vegetative reproduction. Clonal growth of plants is advantageous in unstable environmental conditions (Witte and Stöcklin 2010).

At this stage, the pioneer communities of annual and perennial herbaceous plants are dominated. This stage usually lasts for several years (not more than 10 years). But pioneer communities can exist on steep erosion slopes even during the whole recovery time of over 40 years (Fig. 3.3b).

Next stage of the recovery is determined by the local environmental factors. Ecological selection leads to the formation of plant species groups with similar ecological requirements. Dominant species begin to stand out depending on soil granulometric composition and moisture conditions. The vegetation structure (especially vertical) begins to form in the community. Usually sparse layers of shrubs, herbaceous plants and mosses are already present. For example, willow thickets in wet quarry bottoms are particularly characteristic for this stage (Fig. 3.3c).

Significant changes in the vegetation cover of the quarry occur during the third stage, when recovering vegetation will begin to influence the environment by transformation of main environmental factors such as moisture, light, nutrients and others. For example, the growth of moss cover can keep soil moisture very effective. So, vegetation begins to create special micro environment. Species composition of the community is already similar to those in undisturbed areas. Ruderal species and apophytes have a low frequency and abundance. The features of vertical and horizontal

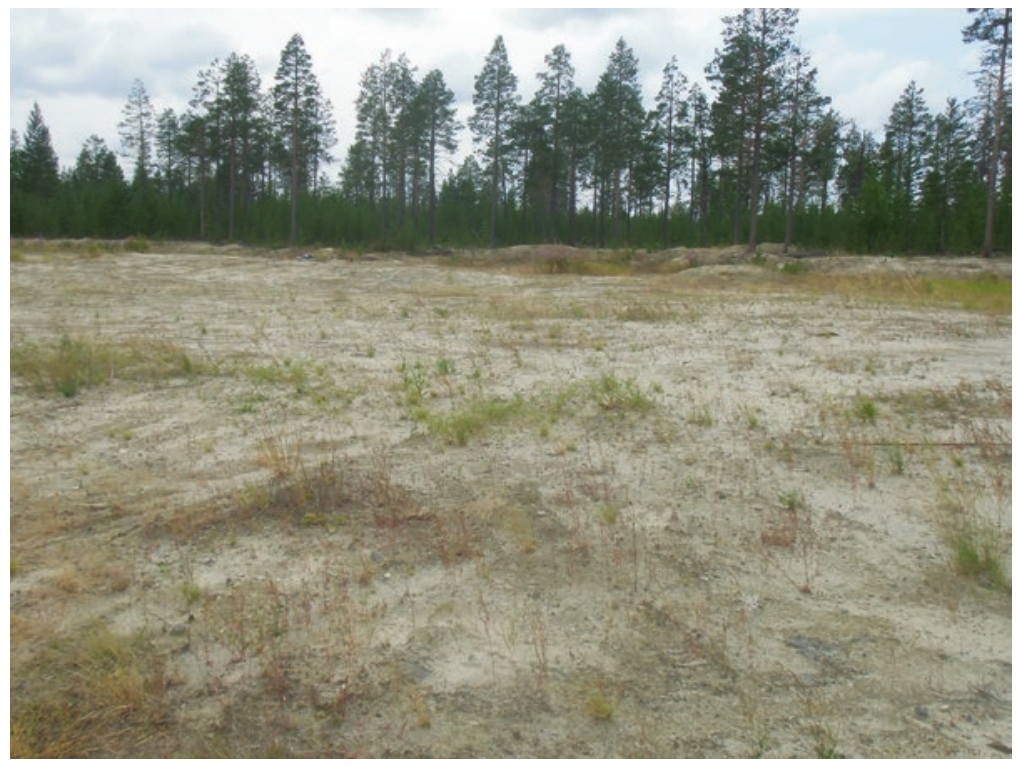

Fig. 3.3a The first stage of the vegetation in recovering quarry, i.e. "ecological chaos" 


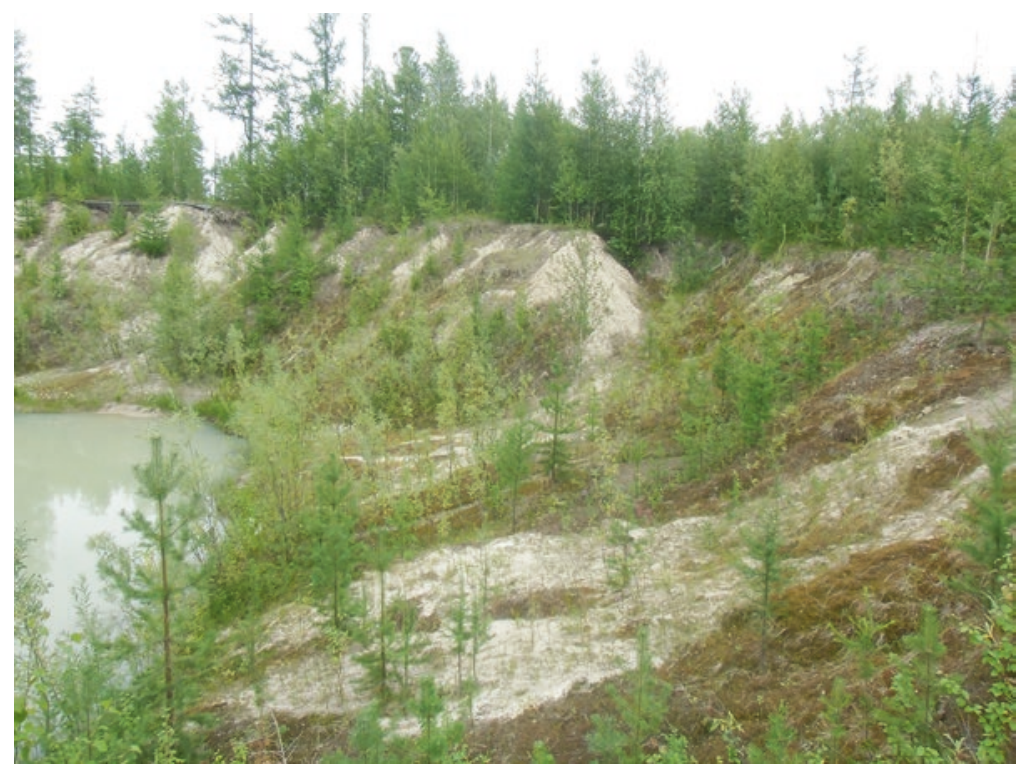

Fig. 3.3b Sparse pioneer vegetation on steep slopes in "old" quarry (whitish spots of soil) (Photographs by: E. Koptseva)

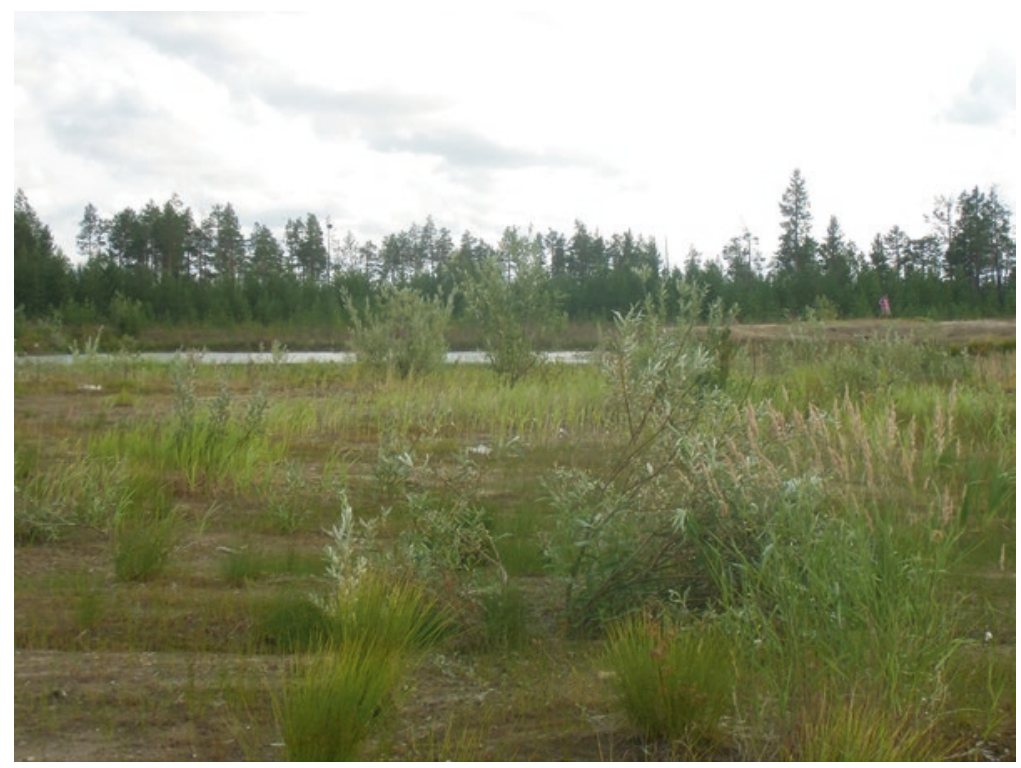

Fig. 3.3c The second stage of natural recovery defined as a community controlled by the environment (Photograph by: E. Koptseva) 

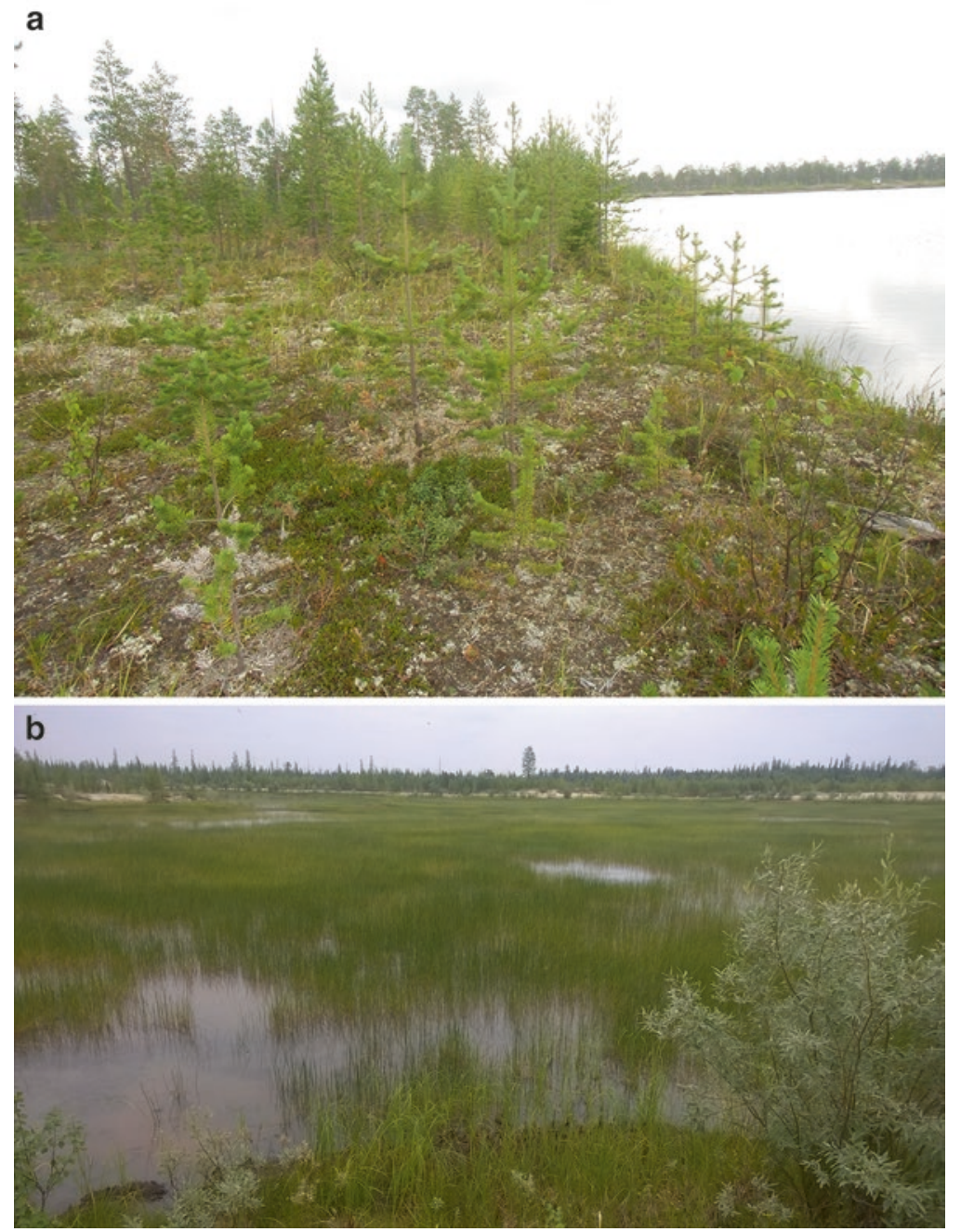

Fig. 3.4 Plant communities in well-drained sites (a) and in wet bottom depressions after 40 years of natural recovery (b) (Photographs by: E. Koptseva)

structure of recovering plant communities begin to emerge more clearly. However, differences between naturally recovering communities from their natural, untouched habitants still exist; for example the lack of balance between the projective cover of dominant plants. On this stage, for example, communities with young woody plants, shrubs, mosses and lichens already occupy well-drained sites (Fig. 3.4a).

Among the plant groups, erosion tolerant plants often prevail in plant cover, for example dwarf shrub Empetrum hermaphroditum Hagerup and lichen Cladonia gracilis (L.) Willd. Communities of this stage are only described in "old" quarries which were decommissioned more than 40 years ago. 
Final recovery stage is associated with transformation to the original condition (as was before the disturbance) and which is basically not observed even in old quarries because restoration of plant production and resource potential requires for a longer time and is still ongoing. For forest-tundra communities the time to reach the final recovery depends on regeneration of tree layer, with the dominance of native coniferous tree species. After 40 years of natural recovery, only the vegetation of a damp floor of the quarry has returned to resemble closest to the undisturbed fens (Fig. 3.4b).

Finally, during natural recovery, quarry area looks like a mosaic of biotopes, each of which is occupied by the most appropriate type of vegetation. In our investigation we observed that dry young pine forests with lichens can regenerate only in well-drained tops, sedge and cottongrass fens in stagnant water sites, and willows in flooding positons. Zonal features of vegetation can be observed in recovering plant communities on the steep slopes. Young larch and spruce trees as well as some shrubs (for example cranberries) can settle on the sloping positions as in Fig. 3.3c.

Key features of the natural recovery such as species composition of vascular plants and cryptogams, as well as the ratio of main plant morphology groups (woody plants, forbs, graminoids) change in time. In quarries, the diversity of plant species and their morphology is significantly different from undisturbed zonal habitats especially at the beginning of primary succession. Usually herbs predominate in vegetation of quarries during the first five-ten years, but proportion of woody plants is substantially reduced. In time the ratio between the different types of plants in vegetation cover changes. The proportion of woody plants progressively increases, while part of forbs and graminoids instead decreases. However even in "old" quarries (after 40 years) the ratio between the different types of plants differs from zonal undisturbed communities (Fig. 3.5a).

Increase in the number of plant species is usually observed in the initial stages of primary succession. This process is accompanied by the increasing of number of different types of plant communities. The maximum number of species and the biggest variety of plant communities are observed after 9-13 years from the beginning of natural recovery. After that, the diversity of plant species and their composition decrease due to environmental selection (Fig. 3.5b).

\subsubsection{Artificial Restoration of Vegetation}

It was shown that vegetation differs from natural one even in "old" quarries that have recovered more than 40 years. Despite the positive successional trends, natural recovery is difficult in the extreme climatic conditions of the Siberian North. Artificial restoration is a mandatory requirement of Russian environmental law. Usually it consists of two phases: engineering and biological restoration.

Before the biological phase of the restoration, the surface of the quarry needs to be levelled out. The reduction of the inclination of the quarry makes the slopes more resistant to erosion ( $\max .20^{\circ}$ slope). This is called as the engineering phase of restoration. The biological stage is to apply peat, fertilizer and plants. 
a

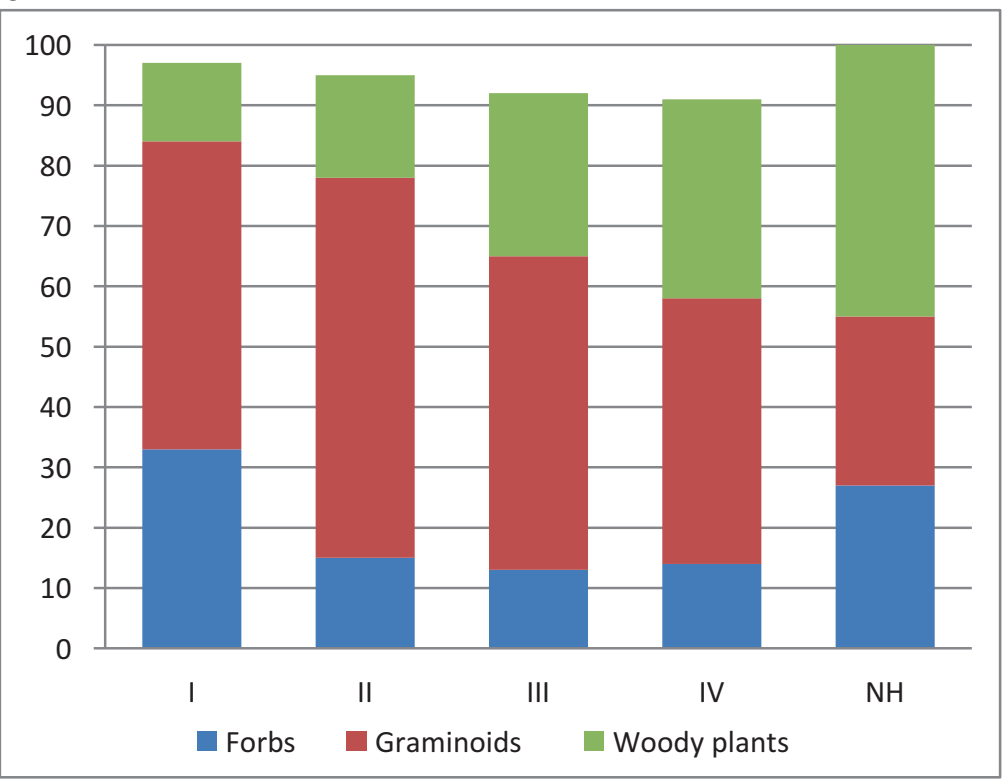

b

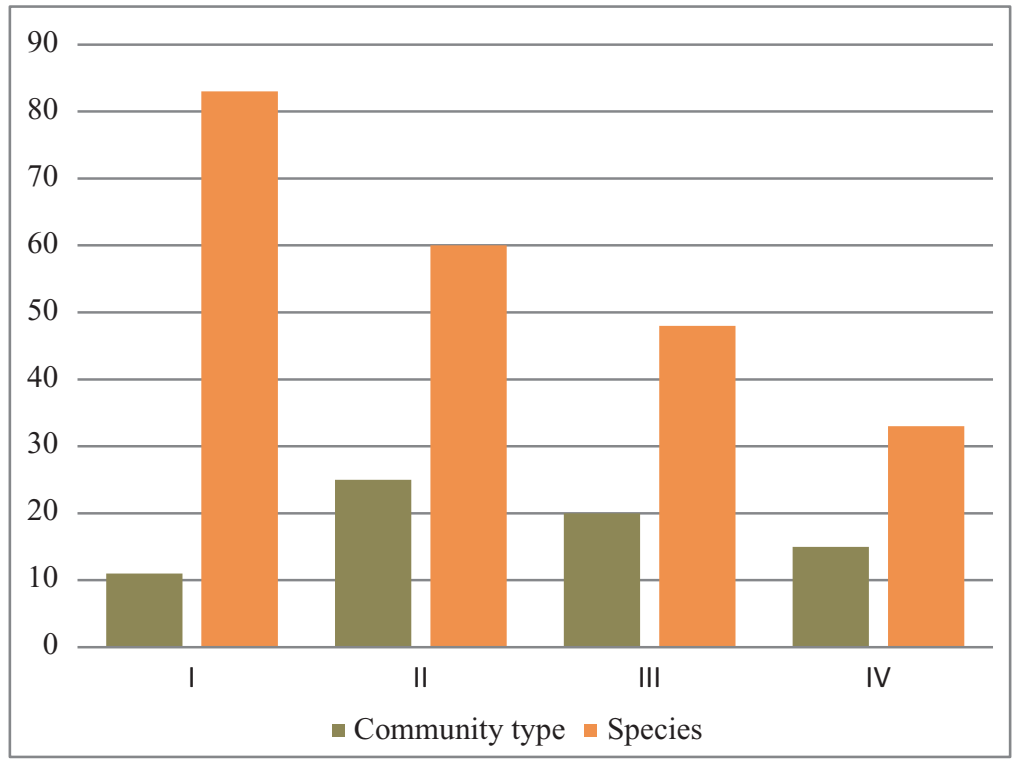

Fig. 3.5 Transformation of basic community parameters in primary succession: (a) - the proportion of the different types of vascular plants in the quarries and in natural habitats $(\mathrm{NH}) ;(\mathbf{b})-$ the number of plant community types and a number of species. Recovery stages: $I$ ecological chaos, II the second stage, $I I I$ the third stage; $I V$ the final stage 
Taking into account the topography of disturbed sites, using a specifically prepared fertilizer mixture and high quality seeds and seedlings is the only effective way of restoration. For example, near Nadym, vegetation of the quarry was restored by pine cultures (Pinus sylvestris L. subsp. lapponica (Fries ex Hartm.) Hartm. ex Holmb.). Dry and semi-dry young pine forests with moss and lichen cover were formed already after 15 years from the beginning of the restoration (Fig. 3.6a).

Unfortunately, planting of forest cultures is used quite rarely in the Yamal-Nenets district. Most often, the artificial restoration in the region is focused on the sowing of perennial grasses and legumes. This is so-called stimulation of natural regeneration. At the same time, it should be remembered that too dense and high grass cover can prevent the germination of native species including forest shrubs, mosses and lichens. In such case, communities with young pine trees and dense grass cover are developed after 15 years (Fig. 3.6b).

Artificial restoration makes the recovery more uniform but it reduces the diversity of biotopes available for formation of different vegetation types. In addition, the majority of the quarry land-area remains free from vegetation for a long time because a strong northern wind blows the seeds away from the quarry. The presence of pits and shallow depressions instead of completely even surface would contribute to a more active process of overgrow by willow and birch.

At times, attempts to use willow cuttings for slope fixation are being made. Willow species are not demanding on the environment, they have a high vegetative reproduction and they most importantly grow in abundance in surrounding natural vegetation along the riverbanks. As natural recovery demonstrated, in spite of high ecological tolerance willow cuttings take root most successfully only in the bottom of the quarry or in lower part of slopes in wet conditions, but not in long stagnant water. Flat and dry surfaces are not suitable for reforestation by willow cuttings (Fig. 3.7a). Similarly, stagnant water sites are unfavorable for the planted young pine trees (Fig. 3.7b). In both of these cases the natural changes of communities by more adapted to existing environmental factors has occurred.

\subsection{Conclusions}

This research showed that intensive methods of restoration are required in northern regions of Russia in order to the speedy return of the disturbed lands to any further use. As shown, the natural recovery continues for a long time, spanning over many decades. Effective restoration can help to avoid the ecological chaos stage, makes the succession of vegetation more manageable and finally intensifies the recovery. However, in each case of restoration a thorough preliminary analysis of existing conditions in these disturbed sites is necessary for choosing the most appropriate methods for the restoration. Underestimation of the effect of environmental conditions may considerably reduce the restoration effectiveness and even lead to financial losses if the restoration fails.

Altogether, a combination of intensive artificial restoration in sites with active surface erosion and promotion of the natural regeneration in the most suitable land- 

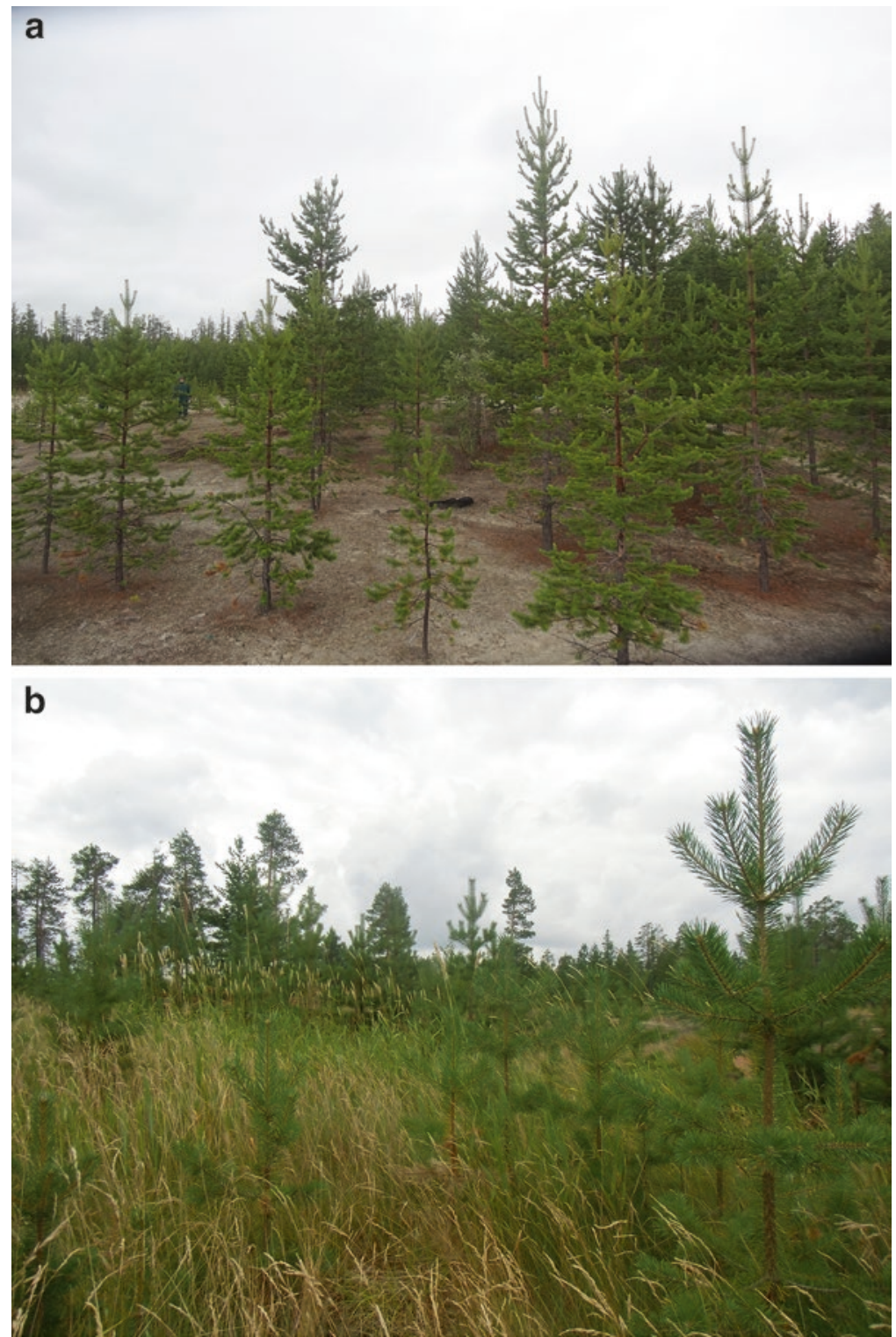

Fig. 3.6 Restoration results: effective pine cultures (Pinus sylvestris L. subsp. lapponica (Fries ex Hartm.) Hartm. ex Holmb.) in the quarry near Nadym City in 2014 (a); pine self-seeding in dense artificial grassland (b) (Photographs by: A. Egorov and E. Koptseva)

form positions are the most effective methods for restoration. Unfortunately, in the Yamal-Nenets Autonomous District, artificial recovery is limited due to the lack of special forest nurseries and adapted grass mixtures. 

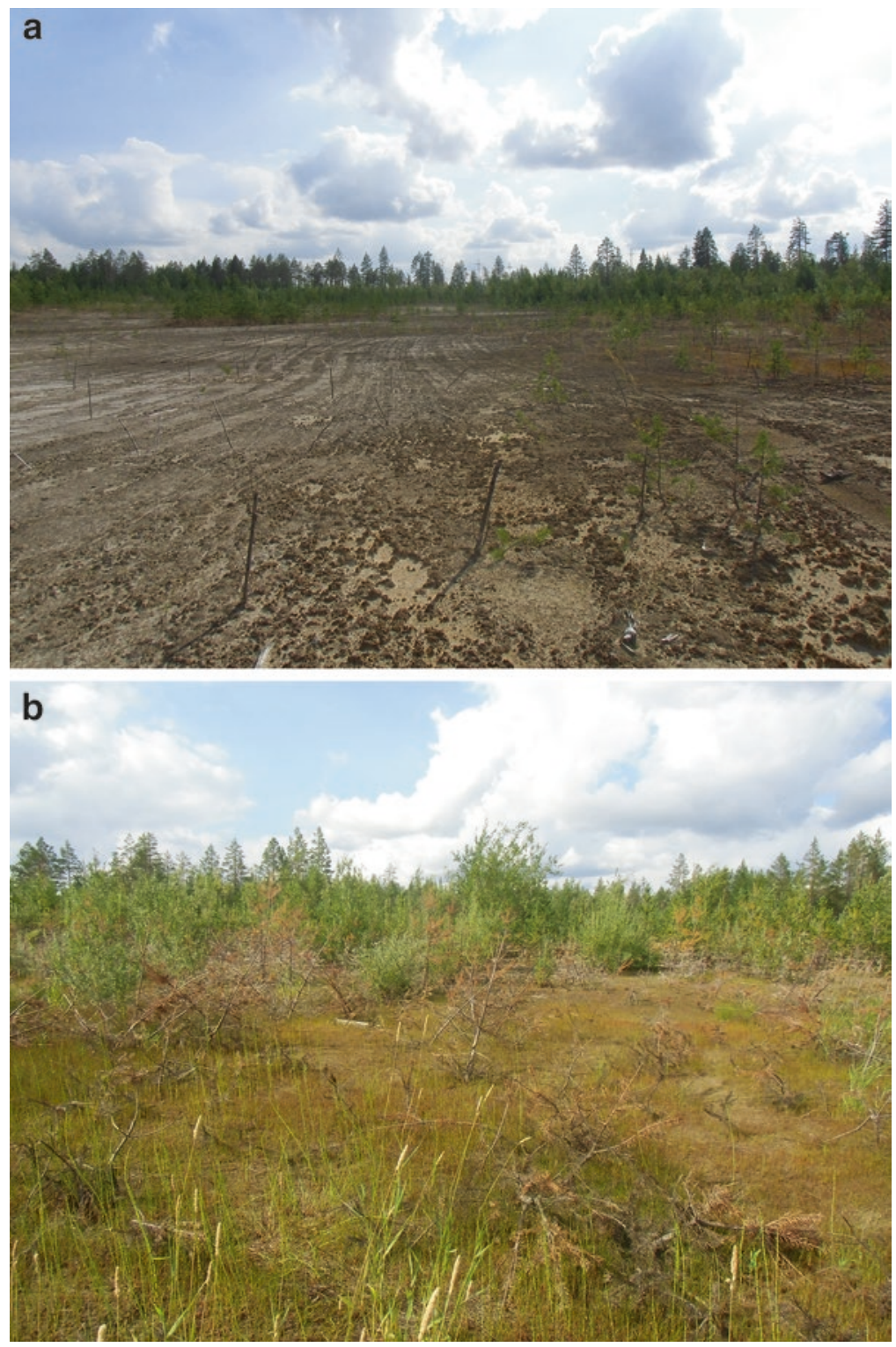

Fig. 3.7 Negative restoration results. Death of willow cuttings and pine tree self-seeding in dry sites (a); Disappearing pine cultures and willow self-seeding in stagnant water sites (b) (Photographs by: E. Koptseva)

Our previous observations (Egorov 2015) and the other investigations have resulted in the following recommendations for successful restoration of quarries in the forest-tundra and forest zones of the Yamal-Nenets Autonomous District: 
- Add peat or forest fertile soil in sufficient quantity.

- Take into account the possibility of erosion even on plots with a slight slope angle.

- Plant annual and perennial grasses; use of rapid growth annual grasses which create protection for perennial species to stabilize soil surface.

- Use of adapted adventive and native plant species.

- Use of leguminous plant species for increasing soil fertility.

- Ensure sufficient tree density during planting.

Acknowledgements This work was supported by the Department of Science and Innovation of the Yamalo-Nenets Autonomous District (grant № 01-15/4, 25.07.2012).

\section{References}

Abakumov EV, Maksimova EI, Lagoda AV, Koptseva E (2011) Soil formation in the quarries for limestone and clay production in the Ukhta region. Eurasian Soil Science. T. 44. № 4. C. 380-385

Barrington M (1927) Cajander's Theory of forest types. Ecology 8(1):135-137

Borgergard S-O (1990) Vegetation development in abandoned gravel pits: effects of surrounding vegetation, substrate, and region. J Veg Sci 1:675-682

de Witte LC, Stöcklin J (2010) Longevity in clonal plants: why it matters and how to measure it. A review. Ann Bot 106:859-870

Egorov AA (2015) Features recultivation quarries in the forest-tundra and forest zone of north of Western Siberia. Natural resources and integrated development of coastal areas in the Arctic zone: materials of International scientific conference (29.09-01.10 2015, Arkhangelsk) Arkhangelsk. P. 112-116. (in Rus)

Forbes BC, Ebersole JJ, Strandberg B (2001) Anthropogenic disturbance and patch dynamics in circumpolar Arctic ecosystems. Conserv Biol 15(4):954-969

Soil Sampling and Methods of Analysis (2008) Soil sampling and methods of analysis, Second Edition. Edited by M.R. Carter and E.G. Gregorich. Canadian Society of Soil Science. 1224 p

Sumina OI (1998) The taxonomic diversity of quarry vegetation in North-West Siberia and Chukotka. Polar Geogr 22(1):17-55

Walker LR, del Moral R (2008) Lessons from primary succession for restoration of severely damaged habitats. Appl Veg Sci 12:55-67

Open Access This chapter is licensed under the terms of the Creative Commons Attribution 4.0 International License (http://creativecommons.org/licenses/by/4.0/), which permits use, sharing, adaptation, distribution and reproduction in any medium or format, as long as you give appropriate credit to the original author(s) and the source, provide a link to the Creative Commons license and indicate if changes were made.

The images or other third party material in this chapter are included in the chapter's Creative Commons license, unless indicated otherwise in a credit line to the material. If material is not included in the chapter's Creative Commons license and your intended use is not permitted by statutory regulation or exceeds the permitted use, you will need to obtain permission directly from the copyright holder. 